\title{
Investigation of Frankfurt's Argument on Moral Responsibility
}

\author{
Tavakkol Koohi Giglou ${ }^{1}$, Javad Danesh ${ }^{2} \&$ Habib Asadi ${ }^{1}$ \\ ${ }^{1}$ Department of literature and Humanities Sciences, Ahar branch, Islamic Azad University, Ahar, Iran \\ ${ }^{2}$ Academy of Islamic Sciences and Culture, Qom, Iran \\ Correspondence: Tavakkol Koohi Giglou, Department of literature and Humanities Sciences, Ahar branch, \\ Islamic Azad University, Ahar, Iran.
}

Received: March 21, 2016 Accepted: April 12, 2016 Online Published: April 27, 2016

doi:10.5539/jpl.v9n3p63 URL: http://dx.doi.org/10.5539/jpl.v9n3p63

This article extracted from the investigation of "Review and critique of the relationship between causal determination and human's moral responsibility from John Martin Fischer's point of view" that to be fulfilled at Islamic Azad university of Ahar, Iran.

\begin{abstract}
The common thought of Christian and Moslem philosophers considers moral responsibility of a person as dependent on his or her ability to choose from several options. However, Harry Frankfurt in his famous paper " alternate possibilities and moral responsibility" challenges freedom condition for moral responsibility with implicit reasons and makes use of several examples to show that it is completely possible for a person to be considered as morally responsible despite failure to access any kind of alternate possible. However, there are two reasons presented by Frankfurt that contrary to his claims show that presence of alternate possibilities or at least imagination for presence of alternatives is the base for responsibility or difficulty of moralactor and if sometimes anactor is regarded as responsible despite absence of alternate possible, this is resulted from his or her "ignorance" of the matter and also the impact of his "intention" in doing action. One of the main defects of theories which deal with moral responsibility conditions is ignoring the intention and purpose of moralactor. This is while ethics domain includes internal actions like intention and will of moral actor as well as apparent actions.
\end{abstract}

Keywords: Frankfurt's argument, intention, moral responsibility, free will

\section{Introduction}

The background of humans philosophical thought believes that moral responsibility depends on the ability to select alternate possible ( Adams, 1986,pp.1-35). Compatibilists and incompatibilists also have differences in some aspects, but they are traditionally in agreement that anactor's ability to act in a different manner than what he or she does at present is necessary for free action and his moral responsibility. Of course, incompatibilists continue to emphasize that in no determined world human cannot perform in a different manner from what he or she has performed. In contrast, compatibilists reason that such a power does exist in human. Anyway, discussion about free determination and moral responsibility is basically focused on this matter:

"is it necessary for an actor to perform in another way if she or he is supposed to be responsible for her or his actions or not?"

Therefore, this thought is very natural that human deserves blame or respect only for an action when he or she had the option to choose from other alternatives. Then, if an actor was able to do an action for which he or she could avoid blame and then he or she did not so, he or she deserves criticism. Further, if he was able to do an action which was less admirable and he did a more admirable action, he deserves appreciation and encouragement. Islamic philosophers also emphasize on necessity of causal precedence, and consider the power and authority of an actor as believe that the ability to select from alternatives is important in an actor's authority fulfillment (Mirdamad, 2002, p.94; Ibn-e-Sina, 1982, p.173; Molla Sadra, 1981.vol3, p.307). According to this common consideration, an actor who has done something unacceptable under conditions like inevitable enforcement of another person, hypnotism, subliminal ads, brainwashing unexpected and uncontrollable diseases like epilepsy and for example hurts his neighbor does not have any moral responsibility because he did not have any other alternative and did not act freely. Therefore, there has been a non-challengeable principle among 
philosophers:

FW: an actor is only responsible for what he or she has done freely.

An analysis of this principle results in the famous rule called "Principle of Alternative Possibilities" which is so axiomatic and not doubtable that it seems impossible to be challenged:

Principle of alternatives possibilities (PAP): the actor is morally responsible for his actions only when he had had other alternatives and could make different decisions

(Otuska,1998,vol.110, pp.685-701).

It is clear that the actor's ability to act in a different manner is prior to the action, when he was aware of other conditions of moral responsibility. For instance, a driver who drinks a cup of coffee which contains a drug slowing down his performance without being informed is not responsible for slow performance towards avoiding an accident with a pedestrian and should not be blamed because he cannot avoid this accident. He was able to avoid accident by not drinking the coffee or not driving after drinking it. However, he was not and could not be aware of the conditions. However, a driver who is drunk as a result of alcoholic drink overuse will be responsible for his slow performance and response in an accident because he was aware (or was able to be aware) and was able to avoid the accident by not drinking. Therefore, the worry or disagreement of some philosophers with teachings like science and divine determination or causal determinism was the result of possibility for being endangered and avoiding any kind of alternative possibility. The thought that moral responsibility requires real alternative possibility i.e. freedom of determination, selection and possibility to act in another way is an important motivation for incompatibilistic between teachings like divine science or former causal necessity with moral responsibility. It is apparently completely natural and acceptable that if we have only one accessible option we have to do only one action and if we have to do what we do then we did it inevitably and are not responsible for that action. Feinberg compares a person's decision-making for his life with a train which moves on a railroad (Feinberg, 1980, pp. 36-40). In his opinion, real freedom in a person-in a way that is the base of his moral responsibility-is similar to the fact that the train has had more than one railroad in access. If our life is similar to the movement of a train on one single railroad without any other alternative railroad, we no longer deserve praise or criticism for any of our actions. We are actually robots and do not have any selection right and determination.

According to the traditional belief, moral responsibility requires a person to have more than one alternative and the future is like a garden with different paths which can be selected by the person himself and this movement creates a serious difference in the world.

\section{Frankfurt's Argument}

Harry Frankfurt, however, in his famous paper titled:" Alternate Possibilities and Moral Responsibilities" in 1969 challenged the common concept of freedom condition in PAP for moral responsibility. Undoubtedly, Frankfurt's reasoning besides outcome reasoning changed compatibilism discussion in a decisive manner because philosophers who support this viewpoint and believe that moral responsibility or free determination is compatible with causal necessity and determination have tried to prove their claim without confronting with outcome reasoning. Thus, semi-compatibilism era emerged. According to this viewpoint, moral responsibility is compatible with determination and causality, whether it is the best understanding of ability to act in another way or not.

Anyway, PAP principle considers concepts like determinism, emergency and Manipulation in which a person is not able to opt another alternative and does not deserve criticism. However, Frankfurt believes that in such situations, similar conditions and requirements exist which both prompts the person to do an action and makes it impossible for him to avoid it. However,

IRR there might be some conditions which by no means prompt the person to do an action and also these conditions make it impossible for him to avoid the action( Frankfurt, 1969, pp.830-837).

Frankfurt propounds an interesting test for explaining IRR and the test becomes a sample for other philosophers:

"suppose Black wants Jones to perform a particular course of action. Black is ready to do any kind of action to make Jones to fulfill his demand but he prefers not to be clear if not necessary. Thus, he waits until Jones is close to making decision about doing the action and does not do anything unless he understands Jones is going to do an unwanted action. If Jones wants to make such (an unwanted) decision, Black takes effective actions to make sure that Jones have decided to do the action and does exactly what Black wants him to...now assume that Black never has to be clear and perform an action because Jones-due to personal reasons-decides to take exactly what Black wants him to do(see: Ibid, pp.835-836) ." from Frankfurt's opinion, in such IRR scenarios, the actor acts 
freely and solely and therefore is responsible for what he or she has done and he cannot do in another manner. Therefore, it seems that PAP is wrong and we should not consider the type of freedom in moral responsibility as equal to freedom of action in another manner or freedom of avoiding a particular action which is done by a person. Frankfurt's challenging PAP had a considerable impact on subsequent essays on relationship between moral responsibility and freedom of action and determination. Many writers after Frankfurt yielded to Frankfurt's reasoning and his counterexamples. Some compatibilists used his reasoning in criticizing incompatibilism of moral responsibility and freedom related to it( Fischer, 1994, chap 7), while some libertarians try to match moral results of Frankfurt with libertarianistic reformed viewpoints ( Stump, 1990; Mele and Robb,1998, vol 107, pp.97-112) of course, some philosophers also argue that Frankfurt stories and its samples are basically defective( Ginet, 1990, vol 10, pp.403-417;Lamb, 1993, vol90, pp.517-527).

\section{Frankfurt Examples}

In this section, we review some examples of Frankfurt viewpoint which are apparently a more detailed statement of IRR and investigate actor's moral responsibility in them. First, consider "unlucky mayor" example which was referred to by Fischer and Raviza (1991) in a paper titled "responsibility and inevitability"( Fischer, 1991,vol101, pp.258-259) and we mention it with some small changes:

Assume that Babak is very unsatisfied with tax programs of the mayor of his city and decides to murder him because he does not have any solution to change him. Although these reasons are not so acceptable and plausible but are convincing for Babak and of course Babak has neither been brainwashed nor received hypnotism and also he has not been under another person's pressure but he has planned for murdering the mayor calmly.

Further, Babak tells about his plot to his reliable friend Ahmad. Babak is an evil person but Ahmad is worse than him because not only he is satisfied with the evil plot because of his personal spite towards the mayor but also he considers a more dangerous plan. He is worried about Babak feeling doubtful about killing the mayor. Therefore, he plants a device secretly in Babak's brain to monitor all Babak's brain reactions and manipulate the reactions if necessary. This device is activated by brain's electronic stimulation and Ahmad's aim to plant it into Babak's brain is to make Babak kill the mayor if he possibly doubts about murder. anyway, Babak and Ahmad go to municipality building and Babak kills the mayor according to his own plot without any doubt and Ahmad thus makes no intervention in the murder. in this example, Babak is morally responsible for killing the mayor, although he did not have any alternate possibility and was not able to avoid this action. In fact, if he refrained from his decision, the device planted by Ahmad in his brain made him to kill the mayor. Thus, when responsibility undermining actor affects alternate trend of action and the occurred trend of action is not affected by it, the actor is morally responsible for his action, although he cannot act in another manner. Although Frankfurt does not specify how examples like "unlucky mayor" provide arguments for rejecting PAP, Widerker believes that two types of reasoning can be inferred from his paper( Widerker, 2000, pp.181-201).

The first reasoning considers Ahmad's passivity towards Babak's action. As we see, Ahmad's presence is not important in Babak's decision to kill the mayor. That is to say, even if Ahmad did not look for an opportunity to intervene, Babak would decide to kill the mayor. We consider an ordinary example of mayor assassination in dealing with this point. In this example, Babak exactly thinks and acts like the previous example but in this example there is nobody like Ahmad to intervene in the action. Now, add Ahmad's presence to this ordinary assassination example like previous example. If Babak is responsible morally for making decision to shoot the mayor in the ordinary example, why shouldn't we admit that he was responsible for murder in the previous example despite absence of Ahmad? It is clear that Ahmad's presence cannot change Babak's mind and action. However, in the first assassination example, Ahmad's presence makes it impossible for Babak to make another decision and do another action. Thus, Babak's ability to make a different decision does not influence asking him for moral responsibility. Therefore, according to Frankfurt's idea, PAP rule is wrong and moral responsibility freedom condition cannot be analyzed in terms of alternate possibilities. However, the second reasoning considers the excuse "I was not able to act in another way". Examples in which some barriers and components make it impossible for the actor to act in another way, the actor can refer to these barriers for his acquittal. As Frankfurt emphasizes, reference to such facts shows that in these examples, the actor took the action only because he was not able to perform differently(Frankfurt, 1969, pp.837-838). Furthermore, in such cases, the actorstates that he was not effective solely in doing the action. However, in an example like the very Babak the murderer, he cannot bring an excuse and state that he was not able to take a different action. This is because he was not aware of Ahmad's presence and cannot claim that because there was no condition like ordinary scenario he did not perform differently. Therefore, in this example, Babak takes action on his own reasons and cannot refer to the excuse "I couldn't do differently." Moreover, Babak does not have any other excuse. He was not forced, hypnotized or addicted to drugs and was not threatened by another person. Therefore, If Babak does not 
have any excuse and we believe that he is morally responsible, PAP should be wrong in this case. Therefore, for short, two assumptions are proposed regarding wrongness of PAP in the aforementioned reasoning. First, facts which are not related to the fact that why the actor behaved in a particular manner does not have any influence on his moral responsibility for the behavior; secondly, the actor deserves criticism only when two conditions are satisfied: he does something morally wrong on his personal intentions and motivations, and he does not have a good excuse for such an action. Now, we consider another example which can be seen in Frankfurt's works and other supporters of Frankfurt's examples with a small difference( Frankfurt, 1971, pp.5-20). This example is called "presidency election". Assume Reza is a Brain and Nervous System Surgeon with special political tendencies. He planted a chip in Ali's brain experimentally and for future political intentions in a surgery he did on Ali's brain to remove a tumor in 1996. He intends to control and supervise political and social activities of Ali. Ali does not know about it at all. Reza does this control via a complicated and advanced computer in order to control over Ali's behavior in Iranian Presidency Election in 1996. According to his plot, If Ali wanted to cast his vote for NateghNouri, the computer intervened via the chip in Ali's brain to convince him to decide to cast his vote for Khatami and do this in action. However, if Ali decided to vote for Khatami independently, the computer would not perform any command but secretly monitors Ali's behavior. Suppose that Ali makes his decision independently and votes for Khatami and acted just as if there were no chip in his brain.

It seems that we can consider Ali responsible for voting for Khatami, although he was not able to behave in a different manner.

It is clear that Frankfurt examples are presented in an unordinary manner; because we are more or less sure that normally "counterfactual interveners" like Reza (in presidency election example) or Ahmad (in unlucky mayor example) do not exist. However, this very unordinary example teaches us an important point about responsible-maker component in ordinary examples. Considering these examples, it seems acceptable that moral responsibility does not require control with alternative possibility. In fact, we should differentiate between two types of control; a control which involves options and alternate possibility and a control which is not like this and as we can see, moral responsibility does not require the first type control( Zimmerman, 1988, pp.32-34). Assume that I am driving a car. The car works properly and I intend to turn right. I send a message to my motor muscles by which the steering wheel turns and the car turns right well. I assume that I am able to form an intention to divert the car to left. Furthermore, I believe that if I had had such an intention, I was able to turn the steering wheel to left and change my direction in that path. In this ordinary example, although I steer the car right but I am able to turn it left either. Therefore, I have a particular kind of control over car movement. I have a "guidance control" over the car as far as I direct the car to a particular path. Moreover, as far as I am able to control the car in a different path, I have "regulative control" over its movement either. In order to explain these two control concepts and their ratios, consider the second example.

In the other example, like the Frankfurt example, I direct the car naturally to right. The car steering wheel works properly when turning right but all of a sudden the steering wheel goes wrong and breaks down such that if I had tried to turn to another direction, the car would have turned right and moved directly towards the path it now goes.

Since I make an attempt for turning right, the steering wheel worked properly and the car moved just as it would work in case of absence of technical failure. In fact, in this case the car steering by me to right is exactly like the previous car. In this case, just like the healthy car in the first case, it seems that I control car movement to right and I have a steering and guidance control over the car but I cannot prompt it to move in another direction. Therefore, I do not have any control over the car or its movement and do not have any regulative control. In general, we think that directing and regulative controls are along with each other but these Frankfurt examples show that how they can be separated from each other at least in some cases. The actor can have a guidance control without having a regulative control and alternate possibility( Dennett, 1988).

Thus, in spite of the fact that Frankfurt examples are unordinary and irregular examples, they direct us that moral responsibility of human is dependent on a particular type of control which does not involve access to alternate possibility. Therefore, if regulating and guidance controls are accompanied in these examples, the regulative control does not account for moral responsibility. As we see, Frankfurt counterfactual interveners (like Ahmad and Reza in the two previous examples)do not play any role in occurrence of the existing action trend. We could leave out the two interveners from samples and everything would be the same as previous trend. Therefore, if a fact is unrelated to individual's action, it seems that it is not necessary to mention it in evaluation of actor's moral responsibility. Reza is only a counterfactual intervener and if the actor showed a tendency to select and perform in a different manner, he would have intervened and guaranteed the desirable result. Of course, such an action would not happen and it can be called Untriggered ensurer. Therefore, the counterfactual intervener which does 
not do anything in action and does not have any influence on causal trend of the story,will be completely unrelated to moral responsibility of the actor. We saw that the accident device in W2 was also a purely counterfactual intervener and was a "untriggered preemptor" and its elimination did not cause any change in the former trend. Therefore, both untriggered ensurers (like Reza) and untriggered preemptors (like sudden device) are inactive similarly; that is to say, they are counterfactual interveners and are not related to attributions of moral responsibility because moral responsibility is related to the existing events trend and not alternate succession events. Anyway, rejection of PAP by Frankfurt examples provides us with a new route to compatibilism with respect to causal determination and moral responsibility because the person may believe that causal determination is completely compatible with moral responsibility, whether this causal determination requires an actor to have a real ad metaphysical access to alternate possibilities or does not require such a thing. incompatibilists will also disregard apparently insoluble issues about relationship between causal determination and freedom of action in another manner (or real access to alternate possibilities). Considering the importance of threats of causal determination for alternate possibilities, it seems that rejection of PAP releases philosophers from getting stuck in logical dead ends and allows for following these discussions in new frameworks and more dynamic frameworks; The fact that whether causal determination directly rejects moral responsibility or not, that is to say, whether causal determination rejects moral responsibility regardless of considerations related to alternate possibilities. As a result of Frankfurt's reasoning, some philosophers have been convinced that we should reject PAP but many of them have not been convinced by Frankfurt arguments or supporters of Frankfurt compatibilism. Some skepticistsreject the belief that Frankfurt managed to provide examples in which an individual is responsible for something and meanwhile cannot prevent it; therefore, these philosophers emphasize that we are not obliged to leave PAP as a result of Frankfurt arguments. Some other skepticists tend to leave PAP but they emphasize that causal determination rejects moral responsibility for a reason other than elimination of alternate possibilities. Of course, both sides of this discussion unanimously agree that Frankfurt examples-even if they show PAP is wrong-do not prove causal compatibilismdetermination and moral responsibility. However, while Frankfurt compatibilists believe that causal determination does not reject moral responsibility, skepticists emphasize that there is a reason for this because some philosophers believe that causal determination is incompatible with the fact that an individual is the origin of his behavior in a way that it involves his moral responsibility( Pereboom, 2003).

Thus, it seems that that the moral result of Frankfurt stories is that if causal determination rejects moral responsibility, this is not the result of elimination of alternate possibilities and absence of regulative control. It is clear that the fact that moral responsibility does not require regulative control does not lead us to the result that causal determination is compatible with moral responsibility. As Fischer emphasizes in his paper "responsibility and control", it is possible that causal determination rejects moral responsibility directly(Fischer, 1982).

\section{Evaluation of Frankfurt's Argument}

As we saw, Frankfurt's argument tries to reject PAP rule and safeguard moral responsibility of the actor against causal determination (or absolute science and prior divine science). However, it has some small ambiguities and problems. For instance, Frankfurt did not specify that whether his assumed intervener is a conditional intervener whose intervention starts in contrast to the plot ad intention of the intervener causally from the beginning of every action (observable or mental) and blocks unfavorable action or is a "counterfactual intervention" whose intervention starts not because of actor's attempt or starting an action which is against intervener's plot but because of an event which is a certain sign of the fact that the actor will act or select against the intention of the intervener in case of absence of another intervener.

There is also an important problem in Frankfurt's argument and that is contrary to Frankfurt's idea, none of the two statements of indirect reasoning on incompatibility of moral responsibility and causal determinationdoes not reject the responsibility as a result of alternate possibility benefits in case of presence of causal necessity. According to indirect reasoning, causal determination and necessity takes any kind of freedom whether in the existing trend or in alternate trend from the actor. For instance, as we saw in the modal statement, an actor's inability to control previous conditions of the world and natural rules is transferred to his inability to do an action and the actor lacks freedom and authority at the time of doing the action and in other words in existing trend. Moreover, contrary to Frankfurt's claim, his two reasons indicate that alternate possibility existence or at least the imagination to have an alternate possibility is the base for responsibility or moral actor's difficulty and if sometimes an actor is regarded as responsible despite absence of alternate possibility, this is the result of his "ignorance" of the issue and also the impact of "intention" element in doing an action. One of the main defects of theories which deal with analysis of moral responsibility conditions is different forms of indirect, direct and quasi-direct reasoning (like Perbum's four-case argument and Mell's Zygote Argument) in rejection of human 
authority and responsibility and also different regulations of Frankfurt and neo-Frankfurt and finally Fischer's solution in explanation of different types of control and defending semi-compatibilism, ignorance of intention element and moral actor intention, because the domain of morality involves moral actor's intention as well as outer actions. In other words, intention is a kind of voluntary action which is the cause of other human voluntary actions and his soul and mind. It is clear that human action cannot be considered as a moral action regardless of intention and many involuntary actions and mechanisms of an actor cannot be regarded as moral action because they are not affected by prior intention and determination despite they have positive or negative results and their actors cannot be responsible and praised or rejected. As Imam Sajjad says, "(Horr Ameli, 1987, p.87).this shows that no action is valuable unless we consider its intention. However, contrary to Law, the intention for doing or not doing an action is the result for responsibility in morality even if it does not lead to the results. Therefore, we accept this regular intuition that human is responsible in many of his actions and is morally responsible and this responsibility involves freedom of the actor in intention selection and action performance. Anyway, in "unlucky mayor" example, if Babak knew that he did not have any alternative but to kill the mayor, he would not have any alternate intention. But his ignorance allowed for a bilateral intention for doing or not doing the action (murder) for him and Ali can be considered as responsible for his intention for killing the mayor. Thus, to put it more exactly, the actor's responsibility is arisen from presence of possibility for alternates of not having an intention for doing the action. Therefore, we consider a new sample of the example of mayor murder. in this example, just like Frankfurt example, Babak enters municipality building in order to kill the mayor. However, Ahmad intensifies his intervention and sends electronic waves to make him have a particular intention to murder the mayor. In this case, Ali cannot choose an alternative from the beginning and Ahmad is also free. Now that Ali does not have any intention to select an alternate action, whether he is responsible or not? It seems that all alternate actions and selections are synonymous to absence of "freedom" condition for moral responsibility.

\section{References}

Carl, G. (1996). In defense of the principle of alternative possibilities: Why I don't find Frankfurt's argument convincing. Philosophical Perspectives, 10.

David, W. (2000). Frankfurt's Attack on the Principle of Alternative Possibilities: A Further Look. Philosophical Perspectives, 14.

Dennett Daniel, C. (1984). Elbow Room: The Varieties of Free Will Worth Wanting. Cambridge: MIT Press.

Derk, P. (2003). Living without Free Will. New York: Cambridge University Press.

Eleonore, S. (1990). Intellect, Will and the Principle of Alternate Possibilities. In M. Beaty (Ed.), Christian Theism and the Problems of Philosophy, Notre Dame. IN: University of Notre Dame Press.

Harry, F. (1969). Alternate Possibilities and Moral Responsibilities. Journal of Philosophy, 66.

Harry, F. (1971). Freedom of the Will and the Concept of a Person. Journal of Philosophy, 68.

Horr Ameli, Muhammad Ben Husain; Vasaeloshiite Ela Tahsil Masayel Al-Shariat; Qom: institute for Al Al-beit Le-Ehya Al-Sarat, 1987.

Ibn-e-Sina, Hosein Ebn Abdollah, Al-Shafa (Elahiyat), Qom, Library of Ayetollah Almarashi Najafi, 1982.

James, L. (1993). Evaluative Compatibilism and the Principle of Alternate Possibilities. Journal of Philosophy, 90 .

Joel, F. (1980). The Interest of Liberty on the Scales. in Rights, Justice, and the Bounds of Liberty: Essays in Social Philosophy, Princeton, N.J.: Princeton University Press.

Marilyn, A. (1986). The Structure of Ockham's Moral Theory. Franciscan Studies XXIV.

Martin, F. J. (1982). Responsibility and Control. Journal of Philosophy, 79.

Martin, F. J. (1994). The Metaphysics of Free Will. Cambridge: Blackwell Publishers.

Martin, F. J., \& Mark, R. (1991). Responsibility and Inevitability. Ethics 101.

Mele Alfred, R., \& David, R. (1998). Rescuing Frankfurt-Style Cases. Philosophical Review, 107.

Michael, O. (1998). Incompatibilism and the avoidability of blame. Ethics, 108.

Mirdamad Muhammad Bagher, Mirdamad works, Tehran, association of cultural works and celebrities, 2002, volume 1 . 
Molla Sadra, Sadr-aldinShirazi, Al-hekmat Al-mota'aliyat fi Al-Asfar Al-Aghliyat Al-Arba'at, Beirut, 1981, volume 6 .

Zimmerman Michael, J. (1988). An Essay on Moral Responsibility. Totowa NJ: Rowman\& Littlefield.

\section{Copyrights}

Copyright for this article is retained by the author(s), with first publication rights granted to the journal.

This is an open-access article distributed under the terms and conditions of the Creative Commons Attribution license (http://creativecommons.org/licenses/by/3.0/). 